\begin{tabular}{c} 
Brazilian Journal \\
of Chemical \\
Engineering \\
\hline
\end{tabular}

ISSN 0104-6632

Printed in Brazil

www.abeq.org.br/bjche

Vol. 26, No. 03, pp. 563 - 574, July - September, 2009

\title{
EFFECTS OF SCANDIUM DOPING CONCENTRATION ON THE PROPERTIES OF STRONTIUM COBALT OXIDE MEMBRANES
}

\author{
Pingying Zeng ${ }^{1}$, Ran $\operatorname{Ran}^{1}$, Zongping Shao ${ }^{1 *}$, Hai $\mathrm{Yu}^{2}$ and Shaomin $\mathrm{Liu}^{3 *}$ \\ ${ }^{1}$ State Key Laboratory of Materials-Oriented Chemical Engineering, Phone: + (86) (25) 83172256, \\ Fax: + (86) (25) 83365813, Nanjing University of Technology, No.5 Xin Mofan Road, Nanjing, 210009, P.R. China. \\ E-mail: shaozp@njut.edu.cn \\ ${ }^{2}$ Chemical Engineering, The University of Newcastle, Callaghan, NSW 2308, Australia. \\ ${ }^{3}$ Department of Chemical Engineering, Phone: + (61) (8) 92669056, Fax: + (61) (8) 92662681, \\ Curtin University of Technology, Perth, WA 6845, Australia. \\ E-mail: Shaomin.Liu@curtin.edu.au
}

(Submitted: January 25, 2009 ; Revised: March 31, 2009 ; Accepted: April 27, 2009)

\begin{abstract}
Perovskite-type mixed conducting oxides of $\mathrm{SrCo}_{1-\mathrm{y}} \mathrm{Sc}_{\mathrm{y}} \mathrm{O}_{3-\delta}(\mathrm{y}=0.02-0.7)$ were synthesized by a combined EDTA-citrate complexing method. Different scandium doping concentrations in $\mathrm{SrCo}_{1-y} \mathrm{Sc}_{\mathrm{y}} \mathrm{O}_{3-\delta}$ have significant effects on the phase structure, electrical conductivity, surface properties and oxygen permeation behaviour of the resultant membranes. $\mathrm{SrCoO}_{3-\delta}$ without scandium incorporation displayed a $2 \mathrm{H}$ $\mathrm{BaNiO}_{3}$-type structure with almost zero oxygen flux at high temperatures. Small amounts of $\mathrm{Sc}_{2} \mathrm{O}_{3}$ doping $(y<0.1)$ efficiently stabilized the oxide in a cubic perovskite structure, leading to a sharp increase in the permeation flux, with a maximum value of $3.1 \mathrm{ml} . \mathrm{cm}^{-2} \cdot \mathrm{min}^{-1}$ achieved at $900^{\circ} \mathrm{C}$ for $\mathrm{SrCo}_{0.95} \mathrm{Sc}_{0.05} \mathrm{O}_{3-\delta}$ and $\mathrm{SrCo}_{0.9} \mathrm{Sc}_{0.1} \mathrm{O}_{3-\delta}$ membranes. The permeation process could be rate-limited by either the oxygen bulk diffusion, oxygen surface exchange, or a combination of both depending on the scandium doping level. Further increases of the $\mathrm{Sc}^{3+}$ doping concentration $(\mathrm{y}>0.1)$ were found to lower the membrane oxygen fluxes, with $\mathrm{y} \geq 0.4$ doped $\mathrm{SrCo}_{1-\mathrm{y}} \mathrm{Sc}_{\mathrm{y}} \mathrm{O}_{3-8}$ ceramics no longer showing any oxygen permeation.

Keywords: Perovskite; Mixed conduction; Oxygen separation membrane; Rate limiting.
\end{abstract}

\section{INTRODUCTION}

Oxygen is one of the most important chemicals used in industry today. Up to now, it is mainly produced from the cryogenic distillation of air, which is only economically attractive for large-scale applications. A potential alternative technique is through the use of ceramic oxygen permeating membranes (Kovalevsky et al., 1998; Tong et al., Ishihara et al., 2002), which are composed of mixed ionic and electronic conducting (MIEC) oxides. Such membranes have $100 \%$ oxygen permeating selectivity (Tsai et al., 1997; Shao et al., 2001; Shaula et al., 2003; Lu et al., 2006; Fagg et al., 2007). The envisaged advantages of oxygen production via ceramic membrane technology include high sizeflexibility, and capability for continuous production of oxygen with substantial reductions in energy consumption (Hendriksen et al., 2000; Bouwmeester, 2003). However, the successful application of the MIEC membrane technology in the oxygen industry strongly depends on the development of highperformance membranes.

Oxygen permeation flux is one of the most important parameters of this technology and is usually considered first in the development of MIEC membranes for commercial application purposes (Tsiakaras et al., 1998; Yaremchenko et al., 1999).

*To whom correspondence should be addressed 
Different from porous ceramic membranes, for which the gas permeability is very structurally dependent (such as pore size and pore size distribution); the oxygen permeability of MIEC membranes is more material-related. Therefore, the development of new materials with high oxygen permeability and phase stability has been the major effort of most researchers in the related field (Bouwmeester, et al., 1992; Shao et al., 2001; Diethelm et al., 2003; Qi and Lin, 2003; Diethelm and Van Herle, 2004; Deng et al., 2004; Kim et al., 2005; Schiestel et al., 2005).

MIEC ceramic materials usually have defined phase structures, which can be derived from perovskite, brownmillerite, fluorite, and others (Kruidhof et al., 1993; Shao et al., 2000; Kharton et al., 2001, 2002; Wiik et al., 2002; Fan et al., 2007). Among them, the perovskite membranes exhibit the highest permeability and greatest potential for improvement [Boginsky, 1998; Ishihara et al., 2000; James et al., 2004]. The doping strategy has been widely applied to improve the permeation properties of the perovskite membranes with dopant choice and dopant level having a significant effect on the lattice structure, electrical conductivity, sintering behaviour, oxygen permeation flux, and even the rate-determining step of the membranes (Zhu et al., 2004; Tong et al., 2003; Trofimenko et al., 1997; Zeng et al., 2007, 2008).

Recently we have demonstrated that $\mathrm{SrSc}_{0.05} \mathrm{Co}_{0.95} \mathrm{O}_{3-\delta}$ is a promising material for oxygen permeating membranes, showing high oxygen permeability at high temperatures (Zeng et al., 2007). Inspired by this finding, our research work in this study is on further developing scandium doped $\mathrm{SrCoO}_{3-\delta}$ for ceramic membrane applications, investigating a series of composite oxides with the nominal composition of $\mathrm{SrCo}_{1-\mathrm{y}} \mathrm{Sc}_{\mathrm{y}} \mathrm{O}_{3-\delta} \quad(\mathrm{y}=0 \sim 0.7)$, achieved by varying the scandium doping level on the B-site. The impact of $\mathrm{Sc}^{3+}$ doping level on the oxygen permeability and the rate-determining step(s) of the membranes is emphasized in this study.

\section{EXPERIMENTAL}

\section{$\mathrm{SrCo}_{1-\mathrm{y}} \mathrm{Sc}_{\mathrm{y}} \mathrm{O}_{3-\delta}$ Powder and Membrane Synthesis}

$\mathrm{SrCo}_{1-\mathrm{y}} \mathrm{Sc}_{\mathrm{y}} \mathrm{O}_{3-\delta} \quad(\mathrm{y}=0 \sim 0.7) \quad$ (SCSy) composite oxides were synthesized by a combined EDTAcitrate complexing sol-gel process with $\mathrm{Sr}\left(\mathrm{NO}_{3}\right)_{2}$, $\mathrm{Co}\left(\mathrm{NO}_{3}\right)_{2}$, and $\mathrm{Sc}\left(\mathrm{NO}_{3}\right)_{3}$ as the raw materials for the metal-ion sources. The detailed information about this wet-chemical process can be found elsewhere
(Shao et al., 2000). Stoichiometric amounts of the metal nitrates were added to an EDTA- $\mathrm{NH}_{3} \cdot \mathrm{H}_{2} \mathrm{O}$ aqueous solution under heating and stirring, followed by the addition of citric acid as the second chelant. The $\mathrm{pH}$ value of the system was controlled at 6 by the addition of $\mathrm{NH}_{4} \mathrm{OH}$ during the whole gel formation process to avoid the deposition of individual metal ions. With the evaporation of water, dark purple gels were obtained, which were preheated at $250^{\circ} \mathrm{C}$ for several hours to form solid precursors and then calcined at $900^{\circ} \mathrm{C}$ in air for $5 \mathrm{~h}$ to obtain the oxides with the aimed composition and lattice structure.

The prepared powders were grounded in a highenergy ball mill (Fritsch, Pulverisette 6), and subsequently pressed into disks or bars by stainless steel dies with a diameter of $15 \mathrm{~mm}$ or dimensions of $5 \mathrm{~mm} \times 8 \mathrm{~mm} \times 25 \mathrm{~mm}$ under a hydraulic force of 30 ton. These green disks or bars were sintered to dense bodies at $1100^{\circ} \mathrm{C}$ for $5 \mathrm{~h}$, respectively. The sintered membranes have a diameter of $12-13 \mathrm{~mm}$ and thickness of $0.7-1.0 \mathrm{~mm}$, while the sintered bars have a dimension of $3 \mathrm{~mm} \times 5 \mathrm{~mm} \times 20 \mathrm{~mm}$. The densities of these membranes were measured by the Archimedes liquid displacement technique. The gas tightness of the membranes was examined by the detection of $\mathrm{N}_{2}$ leakage analysed by gas chromatography.

\section{Characterization}

The phase structure of the samples was investigated using an X-ray Diffractometer (Bruker D8 Advance) with $\mathrm{Cu} \mathrm{K \alpha}$ radiation. The experimental diffraction patterns were collected at room temperature by step scanning in the range of $10^{\circ} \leq 2 \theta \leq 90^{\circ}$. The morphological features of the prepared membranes were examined using an Environmental Scanning Microscope (ESEM, QUANTA-2000). The room temperature oxygen non-stoichiometry was measured by the iodometric titration technique.

The electrical conductivity was measured by the four-probe D. C. method on sintered bars in air upon cooling from $900^{\circ} \mathrm{C}$ to $300^{\circ} \mathrm{C}$ at $5^{\circ} \mathrm{C}$ per step. Silver paste was painted on the square cross sectional edges of the sample or along the rectangular edges (separated by a distance L) to form current and voltage electrodes. Two silver wires acted as current contacts and another two sliver wires acted as the voltage contacts, which were attached to the electrodes using silver paste. The sample was placed in a vertical split tube furnace. A constant current was applied to the two current wires and the voltage response on the two voltage wires was recorded using a Keithley 2420 sourcemeter. The current was 
increased from $1 \mathrm{uA}$ to a maximum value of $2 \mathrm{~A}$.

Dense $\mathrm{Sm}_{0.15} \mathrm{Ce}_{0.85} \mathrm{O}_{1.925}$ pellets with diameter of $12.9 \mathrm{~mm}$ and thickness of $1.0 \mathrm{~mm}$, produced by dry pressing followed by sintering at $1350^{\circ} \mathrm{C}$ for $5 \mathrm{~h}$, were applied as the electrolyte substrates for the impedance test of the membrane materials. Two nominally identical electrodes $\left(1.21 \mathrm{~cm}^{2}\right)$ made from the membrane materials, with a thickness of $\sim 10 \mu \mathrm{m}$ and porosity of $\sim 35 \%$, were deposited on each side of the electrolyte pellet by painting method and calcined at $1000^{\circ} \mathrm{C}$ for $5 \mathrm{~h}$ in air. Impedance measurements were performed using an electrochemical workstation based on a Solartron $1260 \mathrm{~A}$ frequency response analyser in combination with a Solartron 1287 Potentiostat/Galvanostat. The two-electrode cells were tested at open circuit voltage. In general, the electrochemical tests were performed from $850^{\circ} \mathrm{C}$ to $500^{\circ} \mathrm{C}$ in $25^{\circ} \mathrm{C}$ intervals in air, in the frequency range of $0.01-105 \mathrm{~Hz}$ and applied AC voltage amplitude of $10 \mathrm{mV}$.

\section{Oxygen Permeation Study}

Oxygen permeation properties of the membranes were investigated using a high-temperature oxygenpermeation apparatus as shown in Figure 1. Both surfaces of the membranes were carefully polished using a 1000 mesh $\mathrm{SiC}$ sand paper to a thickness of $0.91 \mathrm{~mm}$ and sealed to quartz tubes with silver paste. The effective membrane area for permeation study is $0.45 \mathrm{~cm}^{2}$. The oxygen permeation properties were investigated using the gas chromatographic method by applying ambient air as the feed side atmosphere and helium as the sweep gas to carry the permeated oxygen to a Varian 3800 gas chromatograph equipped with a $5 \AA$ molecular sieve capillary column for in-situ gas composition analysis. All values of oxygen permeation fluxes or other gas flowrates mentioned in this paper were calculated at the conditions of standard temperature and pressure (STP).

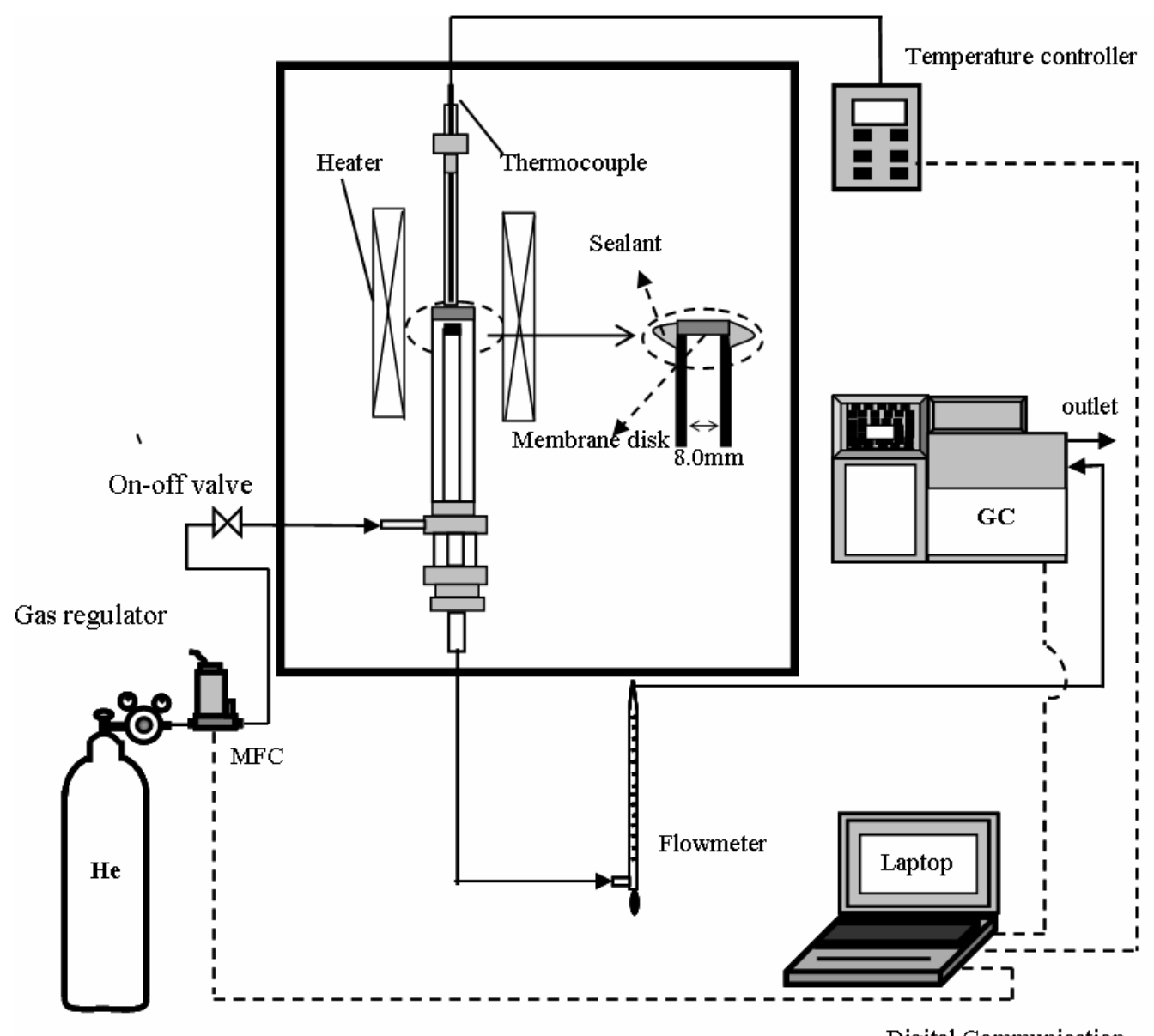

Gas cylinder

Digital Communication

Figure 1: The set-up for the oxygen permeation measurement 


\section{RESULTS AND DISCUSSION}

\section{Basic Characterization of the Oxide Powders}

Figure 2 shows the XRD patterns of the SCSy oxides $(0 \leq y \leq 0.7)$, prepared by calcinations of their solid precursors at $850^{\circ} \mathrm{C}$ in air for $5 \mathrm{~h}$. The parent oxide of $\mathrm{SrCoO}_{3-\delta}(\mathrm{SC})$ and the oxides with very low scandium doping concentration, for example SCS0.02 $(\mathrm{y}=0.02)$, demonstrated a typical $2 \mathrm{H}$ $\mathrm{BaNiO}_{3}$-type structure. Oxide $\mathrm{SCS} 0.02$ changed to a brownmillerite structure when the firing temperature was elevated to $1100^{\circ} \mathrm{C}$. However, at higher doping concentrations in the range of 5 to $50 \mathrm{~mol} \%$ ( $\mathrm{y}=0.05$ 0.5 ), the oxides changed to a cubic perovskite lattice structure. A co-existence of perovskite and brownmillerite phases was observed when the doping amount rose to $60 \mathrm{~mol} . \%$ (Figure $2 \mathrm{~b}$ ), while un-reacted $\mathrm{Sc}_{2} \mathrm{O}_{3}$ oxide was detected for an apparent composition of $\mathrm{SrCo}_{0.3} \mathrm{Sc}_{0.7} \mathrm{O}_{3-\delta}$ (Figure 2c). Since the brownmillerite structure is an oxygen vacancyordered structure of the cubic perovskite, together with the fact that no $\mathrm{Sc}_{2} \mathrm{O}_{3}$ impurity phase was detected at $\mathrm{y}=0.6$, the solubility limit of $\mathrm{Sc}^{3+}$ in $\mathrm{SrCoO}_{3-\delta}$ parent oxide is believed to be around
$60 \mathrm{~mol} \%$, which is higher than that reported by Maignan et al. $(\sim 40 \mathrm{~mol} . \%)$ in 2004. This discrepancy may result from the different synthetic methods used. The cubic perovskite structure of SCSy $(y=0.05-0.5)$ was found to be stable from room temperature to high temperature under oxygen, air and argon atmosphere, indicating their potential application as oxygen separation membrane. The lattice parameters of all the samples are shown in Table 1. It clearly shows a cell expansion with the increase of $\mathrm{Sc}^{3+}$ doping concentration, which is well understood since $\mathrm{Sc}^{3+}(+0.745 \AA)$ is larger in ionic radius size than the cobalt ions $\left(\mathrm{Co}^{3+}, 0.545 \AA\right.$ (LS), $0.61 \AA$ (HS), and $\mathrm{Co}^{4+}, 0.53 \AA$ ) at the B-site of perovskite. As shown in Table 1, the oxygen nonstoichiometry increases gradually with the scandium doping level. The average valence state of cobalt ions was then calculated based on the obtained corresponding oxygen non-stoichiometry, which decreases gradually with the scandium doping concentration, which is opposite to the case of $\mathrm{SrCo}_{1-}$. y $\mathrm{Nb}_{\mathrm{y}} \mathrm{O}_{3-\delta}$ (Zhang et al., 2008). In the table above, the results suggest that the physical properties of cobalt ions in perovskite are highly sensitive to the type of dopant used.

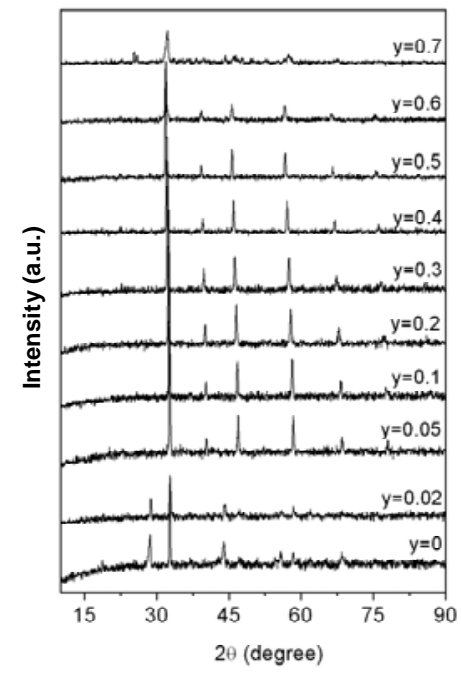

(a)

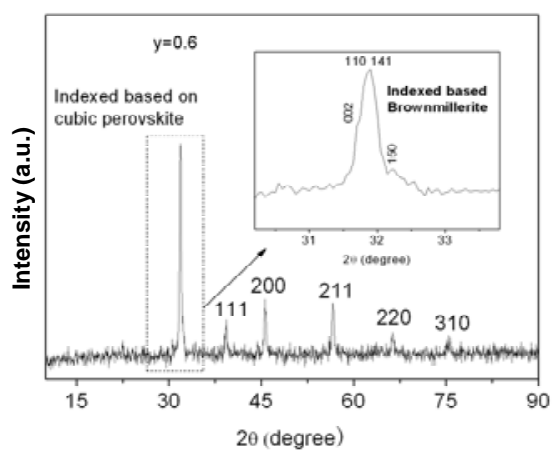

(b)

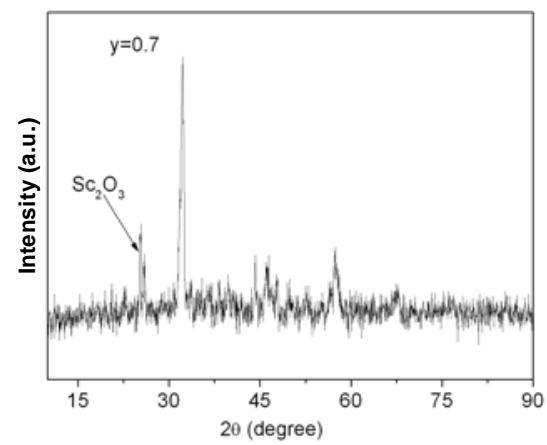

(c)

Figure 2: X-ray diffraction patterns of $\mathrm{SrCo}_{1-y} \mathrm{Sc}_{\mathrm{y}} \mathrm{O}_{3-\delta}$ oxides with different $\mathrm{Sc}$ doping concentration ( $\mathrm{y}=0 \sim 0.7$ ) calcined at $850^{\circ} \mathrm{C}$ (a); Magnified $\mathrm{x}$-ray diffraction patterns of $\mathrm{SrCo}_{0.4} \mathrm{Sc}_{0.6} \mathrm{O}_{3-\delta}$ oxide (b) and $\mathrm{SrCo}_{0.3} \mathrm{Sc}_{0.7} \mathrm{O}_{3-\delta}$ oxide (c) with more details 
Table 1: Lattice constants (d), oxygen nonstoichiometry $(\delta)$ and the average oxidation state of cobalt (x) of the SCSy samples $(y=0.05-0.5)$

\begin{tabular}{|r|c|c|c|c|c|}
\hline $\mathbf{y}$ & Symmetry & $\mathbf{d}(\AA)$ & $\mathbf{V}^{*}\left(\AA^{3}\right)$ & $\mathbf{x}$ & $\delta$ \\
\hline 0.05 & $\mathrm{Pm} 3 \mathrm{~m}$ & $3.8704(2)$ & $57.977(0)$ & $3.074(3)$ & $0.465(4)$ \\
0.1 & $\mathrm{Pm3m}$ & $3.8823(4)$ & $58.515(2)$ & $3.056(2)$ & $0.475(2)$ \\
0.2 & $\mathrm{Pm} 3 \mathrm{~m}$ & $3.9008(5)$ & $59.357(6)$ & $2.882(5)$ & $0.547(5)$ \\
0.3 & $\mathrm{Pm} 3 \mathrm{~m}$ & $3.9213(0)$ & $60.296(2)$ & $2.688(6)$ & $0.609(1)$ \\
0.4 & $\mathrm{Pm} 3 \mathrm{~m}$ & $3.9401(3)$ & $61.167(6)$ & $2.620(0)$ & $0.614(3)$ \\
0.5 & $\mathrm{Pm} 3 \mathrm{~m}$ & $3.9697(2)$ & $62.556(7)$ & $2.528(0)$ & $0.618(0)$ \\
\hline
\end{tabular}

*Unit cell volume

The electrical conductivity of the oxides in air at various $\mathrm{Sc}^{3+}$ doping concentrations, as measured by the 4-probe DC conductivity method, is shown in Figure 3. $\mathrm{SrCoO}_{3-\delta}$ shows a medium level of electrical conductivity between 300 and $900^{\circ} \mathrm{C}$. It increased monotonically from about $3 \mathrm{~S}_{\mathrm{cm}} \mathrm{cm}^{-1}$ at $300^{\circ} \mathrm{C}$ to $30 \mathrm{~S} . \mathrm{cm}^{-1}$ at $900^{\circ} \mathrm{C}$. A minor amount of $\mathrm{Sc}^{3+}$ doping into $\mathrm{SrCoO}_{3-\delta}$ resulted in a substantial increase of the electrical conductivity. The maximum values were reached at a $\mathrm{Sc}^{3+}$ doping concentration of $5 \mathrm{~mol} \%(\mathrm{y}=0.05)$, with higher levels of $\mathrm{Sc}^{3+}$ causing a sharp decrease in the electrical conductivity measured. For example, at $850^{\circ} \mathrm{C}$, the electrical conductivity is $23.6,72,60.2,21.6,5.7$ and $0.85 \mathrm{~S} . \mathrm{cm}^{-1}$ in air, respectively, for SCSy with $\mathrm{y}=0$, $0.05, \quad 0.1, \quad 0.2, \quad 0.3$ and 0.4 . The electrical conductivity is almost zero at $\mathrm{y} \geq 0.5$. When the $\mathrm{Sc}^{3+}$ doping concentration is in the range of 0.02 to 0.1 , the electrical conductivity first increased with temperature then decreased, while a monotonic increase of electrical conductivity with temperature was observed for the others.

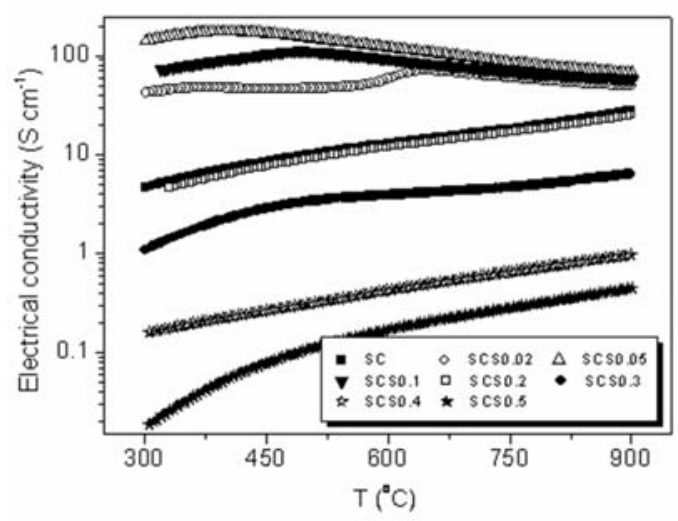

Figure 3: Electrical conductivities of SCSy $(y=0 \sim 0.5)$ under air atmosphere

It is well known that, in the perovskite oxide, the electron conduction is created by B-site lattice cations through strongly overlapping B-O-B bonds with a mechanism like the Zerner double exchange process (Zerner, 1951). The electrical conductivity is closely related with the phase structure and the redox capability of the B-site cations. Since the $\mathrm{SrCoO}_{3-\delta}$ parent oxide showed a distorted $2 \mathrm{H} \mathrm{BaNiO}_{3}$-type phase structure, the Zerner double exchange of an electron between B-site lattice cations was significantly inhibited due to the inefficient overlap. The minor amount of $\mathrm{Sc}^{3+}$ doping resulted in the transition of the phase to a cubic perovskite structure. The $180^{\circ}$ overlap between the outer electron orbital of the B-site metal ions and oxygen ion in the cubic perovskite then greatly facilitates the electron conduction. On the other hand, $\mathrm{Sc}^{3+}$ has a fixed valence state, which acts as a block for the Zerner double exchange of electrons between cobalt ions and oxygen. Therefore, a decrease of electrical conductivity was observed with the increase of $\mathrm{Sc}^{3+}$ doping amount at $y \geq 0.1$. The decreased concentration of the charge carrier also contributed to the reduced electrical conductivity with $\mathrm{Sc}^{3+}$ at $\mathrm{y} \geq 0.05$. Near zero electrical conductivity at $y \geq 0.4$ suggests that the Zerner double exchange between cobalt ions and oxygen was totally blocked by the dilution effect of $\mathrm{Sc}^{3+}$.

\section{Membrane Performances}

To be applied as mixed conducting oxide membranes, the ceramics must be densified to be gastight and display high oxygen permeation fluxes. SCSy pellets with different Sc concentrations ( $\mathrm{y}=0.0-0.6)$ were sintered at $1100^{\circ} \mathrm{C}$ for $5 \mathrm{hr}$. Except for SCS0.02 which shows serious crack formation, all the other samples can be sintered well with complete gastightness and relative density higher than $90 \%$ as measured by the Archimedes method. Figure 4 shows a typical SEM picture of the sintered SCSy membrane with $y=0.1$. The membrane has grain size of about 4 microns. The crack formation in SCS0.02 disks might be related with the phase transition as indicated in its XRD pattern of Figure 2(a). The phase transition may introduce large internal stress during the heating and cooling process. 
The oxygen permeation fluxes of SCSy membranes with varying $\mathrm{Sc}^{3+}$ doping concentration $(y=0.0-0.7)$ between 700 and $900^{\circ} \mathrm{C}$ are shown in Figure 5. All the membranes were controlled at the same thickness of $0.91 \mathrm{~mm}$ and their surfaces were polished by 1000 mesh $\mathrm{SiC}$ sand papers to ensure similar surface morphology. SC membranes show very low permeability between 700 and $900^{\circ} \mathrm{C}$, with a measured permeation flux of only $0.004 \mathrm{~mL} . \mathrm{cm}^{-2}$. $\min ^{-1}$ at $900^{\circ} \mathrm{C}$, which is at the lower detection limit by the GC method. A minor amount of $\mathrm{Sc}^{3+}$ doping into the structure of SC, however, resulted in a significant increase in the oxygen permeation flux of the membrane. For example, it reached as high as $3.1 \mathrm{~mL} \cdot \mathrm{cm}^{-2} \cdot \mathrm{min}^{-1}$ at $900^{\circ} \mathrm{C}$ for SCS0.05 membrane. However, the permeation flux of SCS0.02 failed due to the serious crack formation of the membrane. The SCS0.1 membrane shows comparable permeation flux to that of the SCS0.05 membrane, though the permeation flux deteriorated seriously with any further increase of $\mathrm{Sc}^{3+}$ doping concentration. For example, a permeation flux of $1.7,0.7,0.07 \mathrm{~mL} . \mathrm{cm}^{-}$ ${ }^{2} . \mathrm{min}^{-1}$ was observed at $900^{\circ} \mathrm{C}$ for SCS0.2, SCS0.3 and SCS0.4 membranes, respectively. In contrast, no permeation flux was detected for the membranes with $\mathrm{Sc}^{3+}$ doping concentration of 0.5 or higher, over the whole range of $700-900^{\circ} \mathrm{C}$. The oxygen

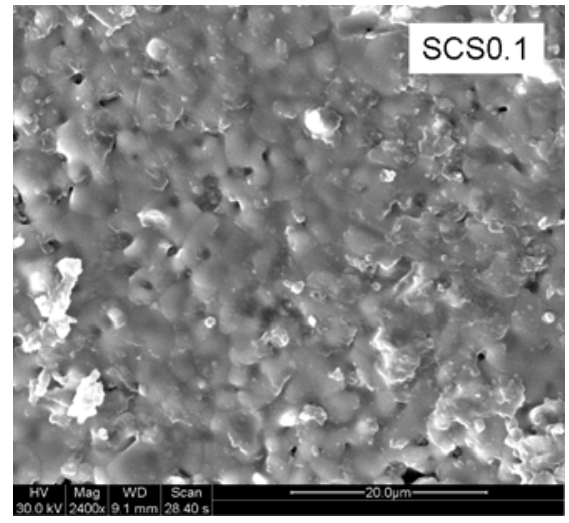

Figure 4: SEM image of SCSy $(\mathrm{y}=0.1)$ membrane sintered at $1150^{\circ} \mathrm{C}$

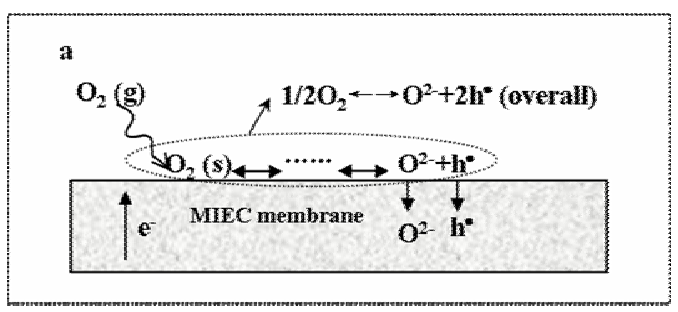

separation through a mixed conducting membrane involves the oxygen exchange over the membrane surfaces (both the feed side and the helium sweep side), and oxygen diffusion and electron transfer through the membrane bulk. Either or both of them could be the rate-determination step.

Electrochemical impedance spectroscopy (EIS) was introduced for assisting the determination of the rate-limiting step(s) of oxygen permeation through SCSy membranes. Figure 6 schematically compares the oxygen reduction over the SCSy electrode based on a symmetric cell configuration and over the MIEC membrane surface. For both cases, they involve the gas phase diffusion, the oxygen surface adsorption, and the dissociation of the oxygen into an oxygen ion and an electron hole over the surface. The dissociated oxygen ions and electron holes migrate through the membrane bulk to the other side of membrane surface of the ceramic membranes, while they incorporate into the electrolyte layer for the symmetric cells. The EIS technique can separate the resistance to oxygen activation over the electrode surface and the resistance to oxygen diffusion through the electrolyte layer. Therefore, the information about the oxygen activation over the electrode can be applied to simulate that on the oxygen permeation membrane surface.

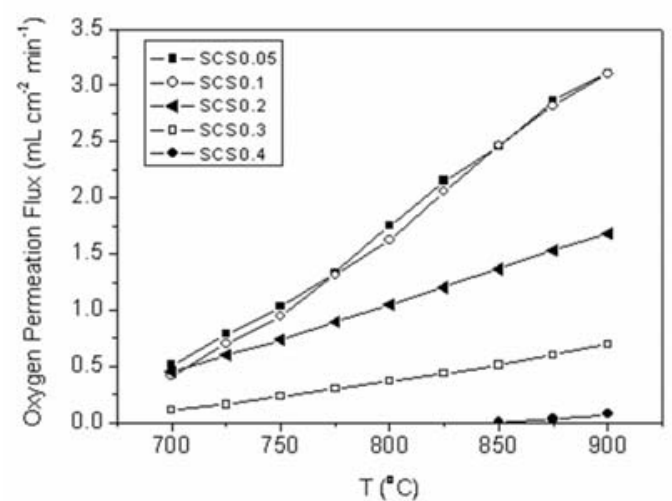

Figure 5: Temperature dependence of oxygen permeation fluxes through SCSy membranes with different Sc doing concentration $(y=0.05 \sim 0.4)$ membranes under an air/helium gradient

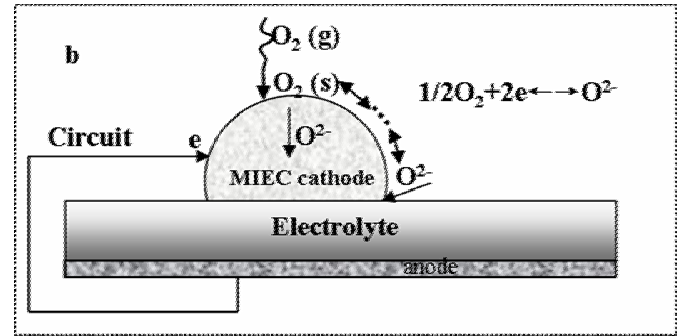

Figure 6: A schematic comparison of oxygen reduction (a) over the surface of MIEC membrane, and (b) over the electrode based on symmetric cell 
It should be mentioned that, in addition to the oxygen reduction over the electrode surface, sometimes the resistance to oxygen diffusion inside the electrode bulk may also be embodied in the ASRs obtained by EIS. The linear relationship of ASRs with 1000/T strongly suggests that the mechanism for oxygen reduction over SCSy electrodes did not change with temperature or scandium doping concentration. The activation energy for oxygen reduction then calculated based on the temperature dependence of ASRs is 156,126 , $106,108,118,114,111$, and $109 \mathrm{~kJ}_{\mathrm{mol}}{ }^{-1}$ respectively, for SCSy with $\mathrm{y}=0.0,0.05,0.1,0.2,0.3$, $0.4,0.5$ and 0.6 . The activation energy for oxygen bulk diffusion through SCS0.05 is lower than $62.1 \mathrm{~kJ}$. $\mathrm{mol}^{-1}$ (Zeng et al., 2007), while a similar activation energy of $106 \sim 120 \mathrm{~kJ} . \mathrm{mol}^{-1}$ was observed for SCSy with y varied from 0.05 to 0.6 , based on the symmetrical cell test. It suggests that the oxygen surface exchange is the rate-limiting step for oxygen reduction over the SCSy electrodes. Therefore, the obtained ASRs can be reasonably applied to the surface exchange process of ceramic oxygenpermeating membranes.

\section{a) $\mathrm{SrCoO}_{3-\delta}$ Membrane}

As demonstrated in Figure 7, $\mathrm{SrCoO}_{3-\delta}$ shows good activity for oxygen reduction. Since zero oxygen permeation flux was actually detected, the rate of the permeation process through the SC membrane is likely determined by the slow bulk diffusion processes (oxygen or electron). Under the bulk diffusion process, the permeation flux can be expressed by:

$$
\mathrm{J}_{\mathrm{O}_{2}}=-\frac{\mathrm{RT}}{4^{2} \mathrm{~F}^{2} \mathrm{~L}} \int_{\ln \mathrm{P}_{\mathrm{O}_{2}}^{\prime}}^{\ln \mathrm{P}_{\mathrm{O}_{2}}^{\prime \prime}} t_{\text {ion }} \mathrm{t}_{\text {el }} \sigma_{\text {total }} \mathrm{d}\left[\ln \mathrm{P}_{\mathrm{O}_{2}}\right]
$$

where $\mathrm{P}_{\mathrm{O}_{2}}^{\prime}, \mathrm{P}_{\mathrm{O}_{2}}^{\prime \prime}$ are the oxygen partial pressures at the oxygen feed side atmosphere and sweep side atmosphere, $t_{i o n}$ is the oxygen ion transference number, $t_{e l}$ is the electron transference number, and $\sigma_{\text {total }}$ is the sum of electronic conductivity and oxygen ionic conductivity.

The measured electronic conductivity of $\mathrm{SrCoO}_{3-\delta}$ reached 16-30 S.cm ${ }^{-1}$ between $700-900^{\circ} \mathrm{C}$. Since the oxygen ionic conductivity is typically less than $1 \mathrm{~S} . \mathrm{cm}^{-1}$, the electronic conductivity is then overwhelming. It suggests that the oxygen bulk diffusion is the main rate-limiting step in oxygen permeation through $\mathrm{SC}$ membrane. It is well known that the $2 \mathrm{H} \mathrm{BaNiO}_{3}$-type structure is a distorted and oxygen vacancy-ordered structure. This structural distortion and vacancy ordering immobilizes the oxygen ion, resulting in negligible oxygen permeation flux for the membrane.

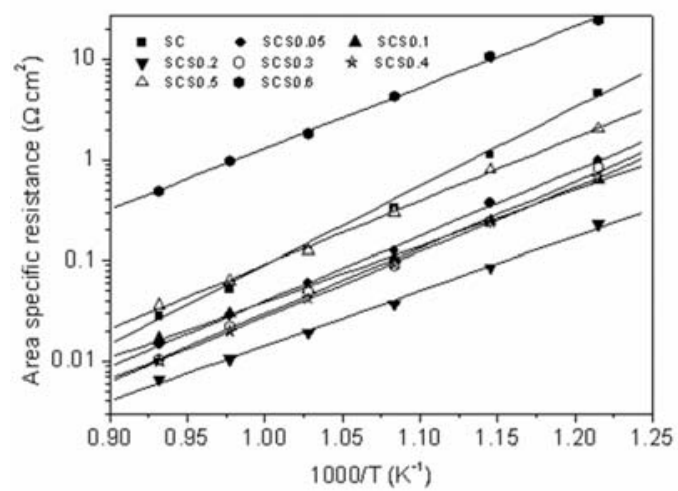

Figure 7: Arrhenius plots of ASRs for SCSy $(y=0.0-0.6)$ in air between 550 and $800^{\circ} \mathrm{C}$

\section{b) SCS0.05 and SCS0.1 Membranes}

As shown in Figures 4 and 5, both membranes possess considerable high electrical conductivities and oxygen permeation fluxes at high temperatures. In previous works, we have demonstrated that the rate of oxygen permeation through the SCS0.05 membrane was determined mainly by the slow oxygen surface exchange kinetics at the conditions of reduced temperature and low oxygen partial pressure of the sweep side atmosphere (Zeng et al., 2007). The transition of the rate-limiting step from bulk oxygen diffusion of the SC membrane to surface exchange of the SCS0.05 membrane is closely related to the sharp increase of the oxygen mobility inside the lattice due to the formation of cubic perovskite structure upon the $\mathrm{Sc}^{3+}$ doping.

The rate-limiting step information can be obtained based on the activation energies (Ea) for oxygen permeation. The activation energy for surface exchange is typically higher than that for oxygen bulk diffusion since the dissociation of oxygen to oxygen ion is much more difficult than the diffusion of oxygen. Table 2 shows the Ea for oxygen permeation through SCSy membranes at different temperatures at fixed $\mathrm{P}_{\mathrm{O}_{2}}^{\prime}$ of $0.21 \mathrm{~atm}$ and $\mathrm{P}_{\mathrm{O}_{2}}^{\prime \prime}$ of $0.0148,0.0078$ and $0.00276 \mathrm{~atm}$, respectively, for $y=0.1,0.2$ and 0.3. For all of them, Ea increased with the decrease of the investigated operational temperature range. When the temperature zone is 
$750-800^{\circ} \mathrm{C}$, the Ea for oxygen permeation through SCS0.1 membrane is around $110 \mathrm{~kJ} . \mathrm{mol}^{-1}$, which is similar to the activation energy for the oxygen surface exchange process $\left(106 \mathrm{~kJ} \cdot \mathrm{mol}^{-1}\right)$, derived based on the temperature dependence of ASRs. It suggests that the rate of the oxygen permeation process for SCS0.1 membrane at $750-800^{\circ} \mathrm{C}$ is mainly determined by the surface oxygen exchange. The decrease of Ea with the increase of operating temperatures suggests that the role of bulk diffusion in the rate-determinating step of the oxygen permeation process is strengthened. It is due to the large improvement of surface exchange kinetics compared to the respective improvement in oxygen bulk diffusion rate with temperature. The above results suggest that the oxygen permeation process for SCS0.1 was rate-limited by the relatively slow oxygen surface exchange kinetics at low operation temperatures $\left(<800^{\circ} \mathrm{C}\right)$, while it is a combination of oxygen surface exchange and oxygen bulk diffusion at higher temperatures $\left(>800^{\circ} \mathrm{C}\right)$.

\section{c) SCSO.2 and SCSO.3 Membranes}

Both of these materials show a medium level of electrical conductivity and oxygen permeability as shown in Figures 4 and 5. Based on the EIS results, however, they possess an improved surface activity for oxygen reduction relative to $\mathrm{SCS} 0.05$ and SCS0.1. The obvious deterioration of oxygen permeation fluxes for both SCS0.2 and SCS0.3 membranes, as compared with SCS0.05 and SCS0.1 membranes, suggests that the role of oxygen bulk diffusion in the rate-determinating step is strengthened for SCS0.2 and SCS0.3 membranes.

The Ea for oxygen permeation through SCS0.2 membrane at different temperatures is also shown in Table 2. The apparent Ea was found to increase with the decrease of the temperature. However, the maximum Ea at $750-800^{\circ} \mathrm{C}$ was only $75.81 \mathrm{~kJ} \cdot \mathrm{mol}^{-1}$, which is much lower than the activation energy for the oxygen surface exchange process $\left(108 \mathrm{~kJ} . \mathrm{mol}^{-1}\right)$, as derived based on the temperature dependence of area specific resistance. It suggests that the oxygen permeation rate through SCS0.2 membrane between 750 and $800^{\circ} \mathrm{C}$ is determined by the combination of oxygen bulk diffusion and the oxygen surface exchange. The decrease of Ea with temperature implies the enhanced importance of the role of bulk oxygen diffusion in the rate-determinating step. The rate-determination information can also be obtained from the $\ln \frac{\mathrm{P}_{\mathrm{O}_{2}}^{\prime}}{\mathrm{P}_{\mathrm{O}_{2}}^{\prime \prime}}$ dependence of permeation flux. As shown in Figure 8, the permeation flux at $800^{\circ} \mathrm{C}$ gradually increased with the increase of $\ln \frac{\mathrm{P}_{\mathrm{O}_{2}}^{\prime}}{\mathrm{P}_{\mathrm{O}_{2}}^{\prime \prime}}$, suggesting that the oxygen bulk diffusion has an important role in the rate determination of the oxygen permeation process at $800^{\circ} \mathrm{C}$ (Zeng et al., 2007). However, at $750^{\circ} \mathrm{C}$, the permeation flux initially increases with the increase of $\ln \frac{\mathrm{P}_{\mathrm{O}_{2}}^{\prime}}{\mathrm{P}_{\mathrm{O}_{2}}^{\prime \prime}}$, and then decreases with the further increase of $\ln \frac{\mathrm{P}_{\mathrm{O}_{2}}^{\prime}}{\mathrm{P}_{\mathrm{O}_{2}}^{\prime \prime}}$. This suggests that the oxygen surface exchange starts to play an important role in the rate determination of oxygen permeation through SCS0.2 membrane at $750^{\circ} \mathrm{C}$.

The higher surface activities, but poorer oxygen permeability, strongly suggests a lower oxygen bulk diffusion rate in SCS0.2 than in SCS0.1. Since SCS0.2 has higher oxygen vacancy concentration than SCS0.05, the defect-association is more likely to occur in SCS0.2. The increased surface activity and reduced bulk diffusion rate then account for the enhanced role of oxygen bulk diffusion in the ratedetermination of the oxygen permeation through SCS0. 2 membrane.

The electrical conductivity of SCS0.3 was only $1.1 \sim 6.3{\mathrm{~S} . \mathrm{cm}^{-1}}^{\text {between }} 300 \sim 900^{\circ} \mathrm{C}$, which is even lower than that of SC due to the blocking effect of $\mathrm{Sc}^{3+}$ on Zerner double exchange between cobalt ions and oxygen. As shown in Figures 4 and 5, both the surface activities for oxygen reduction and the permeation fluxes of the membranes decreased, as compared to the SCS0.2 membrane. As shown in Table 2, the activation energy for oxygen permeation through SCS0.3 membrane is about $90 \mathrm{~kJ} . \mathrm{mol}^{-1}$, which is lower than that for oxygen surface exchange of $114 \mathrm{~kJ} \cdot \mathrm{mol}^{-1}$. It suggests that the rate of the oxygen permeation process through SSC0.3 membrane is also likely to be determined by a combination of surface exchange and bulk diffusion with an increasing importance of bulk diffusion with temperature.

Under bulk diffusion control of the permeation process, the permeation flux through mixed conducting membranes can be simplified to:

$\mathrm{J}_{\mathrm{O}_{2}}=-\frac{\mathrm{RT}}{4^{2} \mathrm{~F}^{2} \mathrm{~L}} \int_{\ln \mathrm{P}_{\mathrm{O}_{2}}^{\prime}}^{\ln \mathrm{P}_{\mathrm{O}_{2}}^{\prime \prime}} \sigma_{\text {ion }} \mathrm{d}\left[\ln \mathrm{P}_{\mathrm{O}_{2}}\right]$ 
The relationship of $\sigma_{\text {ion }}$ and oxygen partial pressure can be followed by the empirical equation:

$$
\sigma_{\text {ion }}=\sigma_{\text {ion }}^{\mathrm{o}} \mathrm{P}_{\mathrm{O} 2}^{\mathrm{n}}
$$

Combining equations (2) and (3) gives:

$$
\mathrm{J}_{\mathrm{O} 2}=\frac{\beta}{\mathrm{d}}\left[\mathrm{P}_{\mathrm{O} 2}^{\prime \prime}-\mathrm{P}_{\mathrm{O} 2}^{\prime}{ }^{\mathrm{n}}\right]=\mathrm{a}\left[\mathrm{P}_{\mathrm{O} 2}^{\prime \prime}{ }^{\mathrm{n}}-\mathrm{P}_{\mathrm{O} 2}^{\prime}{ }^{\mathrm{n}}\right]
$$

where $\beta=-\frac{\sigma_{\text {ion }}^{\mathrm{o}} \mathrm{RT}}{4^{2} \mathrm{~F}^{2} \mathrm{n}}, \mathrm{P}_{\mathrm{O} 2}^{\prime}=0.21 \mathrm{~atm}$

Figure 9 shows the PO2" dependence of oxygen permeation fluxes through SCS0.3 membrane at $900 \mathrm{oC}$. A positive value $(0.167)$ of $\mathrm{n}$ was observed at PO2" $=0.002-0.005 \mathrm{~atm}$, while a negative value of $\mathrm{n}(-$ 0.428 ) was found at $\mathrm{PO} 2^{\prime \prime}=0.005-0.017 \mathrm{~atm}$. Since both the rate of diffusion through oxygen vacancy sites and the concentration of oxygen vacancies increase with the decrease of oxygen partial pressure, a negative value of $\mathrm{n}$ would be predicted if oxygen bulk diffusion is the rate-limiting step based on Eqs.4. The positive value of $\mathrm{n}$ at lower PO2" (i.e., 0.002-0.005atm) indirectly suggests that oxygen permeation was mainly determined by oxygen surface exchange, or a combined oxygen surface exchange and oxygen bulk diffusion at large oxygen partial pressure gradient across the $0.91 \mathrm{~mm}$ thick SCS0.3 membrane.

\section{d) SCS0.4, SCS0.5, and SCS0.6 Membranes}

For SCS0.4, the measured electrical conductivity is less than $1.0 \mathrm{~S} . \mathrm{cm}^{-1}$ in air and less than $0.02 \mathrm{~S} \mathrm{~cm}^{-1}$ in nitrogen between 500 and $900^{\circ} \mathrm{C}$. The oxygen permeation flux of the SSC 0.4 membrane is only $0.073,0.03$ and $0.0092 \mathrm{~mL} \cdot \mathrm{cm}^{2} \cdot \mathrm{min}^{-1}$ at 900,875 and $850^{\circ} \mathrm{C}$, respectively. As compared to the SCS0.3 membrane, the oxygen permeation flux of the SCS0.4 membrane decreased sharply. Since the ASRs of SCS0.4 are comparable to that of SCS0.3, the oxygen bulk diffusion becomes the main ratelimiting step for the SCS0.4 membrane. It implies that the increase of scandium doping level from $\mathrm{y}=0.3$ to $\mathrm{y}=0.4$ sharply reduces the oxygen bulk diffusion rate. It is well known that the dopingrelated disorder induces fluctuations of the elastic as well as the coulomb potential in the crystal lattice and thus creates trapping centres for the anion vacancies, which deteriorate the oxygen mobility in the oxide. The increase of $\mathrm{Sc}^{3+}$ doping level to $\mathrm{y}=0.4$ thus seriously deteriorated the oxygen mobility. With the further increase of $\mathrm{Sc}^{3+}$ doping concentration, zero oxygen permeation flux was obtained. This suggests that the oxygen ion was wholly immobilized, similar to the case of undoped $\mathrm{SrCoO}_{3}$ $\delta$. The near zero electrical conductivity implies that, besides oxygen bulk diffusion, electronic conduction may also play a role in the oxygen permeation process, which is different from the case of a $\mathrm{SrCoO}_{3-\delta}$ membrane.

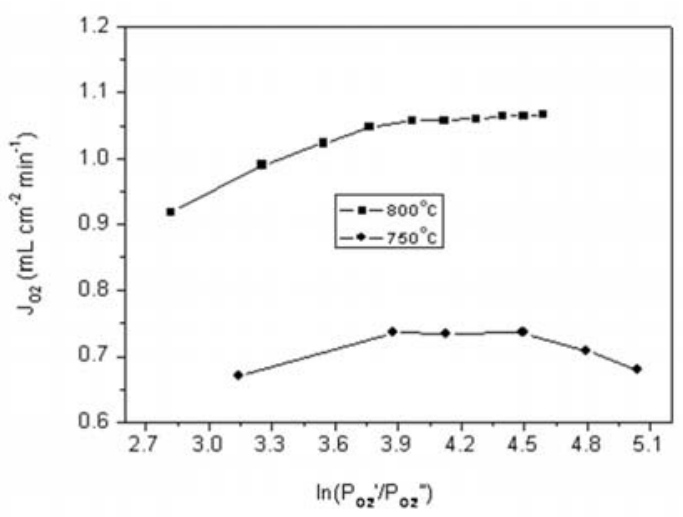

Figure 8: $\ln \frac{\mathrm{P}_{\mathrm{O}_{2}}^{\prime}}{\mathrm{P}_{\mathrm{O}_{2}}^{\prime \prime}}$ dependence on the oxygen permeation fluxes though SCS0.2

membrane at 800 and $750^{\circ} \mathrm{C}$ with ambient air as the feed side atmosphere

Table 2: Activation Energies for oxygen permeation through SCS0.1, SCS0.2 and SCS0.3 membranes with $\mathrm{d}=0.91 \mathrm{~mm}, \mathrm{P}_{\mathrm{O}_{2}}=0.21 \mathrm{~atm}, \mathrm{P}_{\mathrm{O} 2}{ }^{\prime \prime}=0.0148 \mathrm{~atm}, 0.0078 \mathrm{~atm}$ and $0.00276 \mathrm{~atm}$, respectively.

\begin{tabular}{|l|c|c|c|c|}
\hline \multicolumn{2}{|c|}{ Temperature range $\left({ }^{\mathbf{0}} \mathbf{C}\right)$} & $\mathbf{7 5 0 - 8 0 0}$ & $\mathbf{8 0 0 - 8 5 0}$ & $\mathbf{8 5 0 - 9 0 0}$ \\
\hline $\mathrm{Ea}$ & $\mathrm{y}=0.1$ & $110.0 \pm 3.0$ & $96.6 \pm 2.3$ & $80.5 \pm 1.9$ \\
$\left(\mathrm{~kJ} . \mathrm{mol}^{-1}\right)$ & $\mathrm{y}=0.2$ & $75.8 \pm 1.0$ & $68.3 \pm 0.7$ & $60.1 \pm 0.5$ \\
& $\mathrm{y}=0.3$ & $92.6 \pm 0.7$ & $89.9 \pm 1.3$ & $89.6 \pm 2.4$ \\
\hline
\end{tabular}




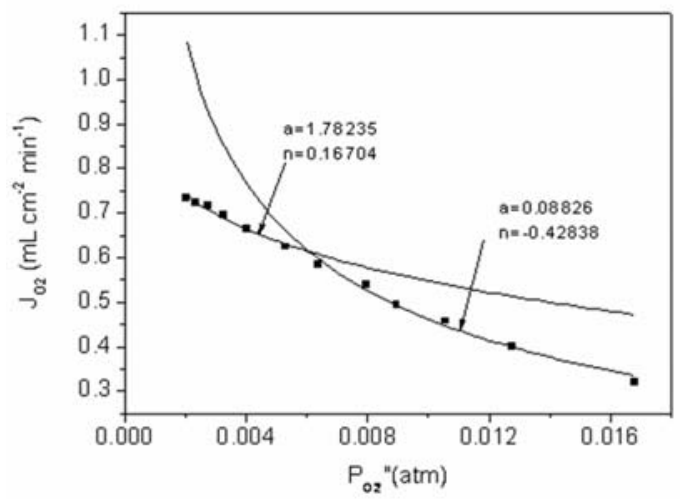

Figure 9: The $\mathrm{P}_{\mathrm{O} 2}$ " dependence of oxygen permeation fluxes through $\mathrm{SCS} 0.3$ membrane at $900^{\circ} \mathrm{C}$ with ambient air as the feed side atmosphere

\section{CONCLUSIONS}

A series of $\mathrm{SrCo}_{1-\mathrm{y}} \mathrm{Sc}_{\mathrm{y}} \mathrm{O}_{3-\delta}(\mathrm{y}=0 \sim 0.7)$ oxides was prepared by a combined EDTA-citrate complexing sol-gel process. A single phase perovskite with a cubic lattice structure was obtained at $y \leq 0.6$. The membrane made from undoped parent $\mathrm{SC}$ oxide shows near zero permeation flux. Small amounts of $\mathrm{Sc}^{3+}$ efficiently stabilized the cubic perovskite structure and resulted in a sharp increase of the permeation flux. SCS0.05 and SCS0.1 membranes showed the highest oxygen permeation flux among the doped membranes with a maximum flux of $\sim 3.1 \mathrm{~mL} . \mathrm{cm}^{-2} \cdot \mathrm{min}^{-1}$ at $900^{\circ} \mathrm{C}$. At $\mathrm{y} \geq 0.1$, the permeation flux started to decrease sharply with the increase of $\mathrm{Sc}^{3+}$ doping amount. The oxygen bulk diffusion was the rate-determining step for the SC membrane, while the SCS0.05 and SCS0.1 membranes were actually rate-limited by the relatively slow oxygen surface exchange kinetics at low operation temperatures $\left(<800^{\circ} \mathrm{C}\right)$. With the further increase of $\mathrm{Sc}^{3+}$ doping concentration, the importance of bulk diffusion in the rate-determining step is enhanced, with a combination of rate limiting oxygen surface exchange and bulk diffusion for the case of both SCS0.2 and SCS0.3 membranes. At $\mathrm{y} \geq 0.4$, the permeation process was again mainly ratelimited by the slow oxygen bulk diffusion.

\section{ACKNOWLEDGEMENTS}

This work was supported by the National Natural Science Foundation of China, under contract No. 20701020, and Natural Science Foundation of Jiangsu Province, under contract No. BK20066180. $\mathrm{Dr}$. $\mathrm{Yu}$ is particularly grateful to the University of
Newcastle, Australia, for providing the research fund under the Independent Investigator Research Scheme for 2008. Dr. Liu acknowledges the ARC fellowship provided by the Australian Research Council.

\section{REFERENCES}

Bouwmeester, H. J. M., Kruidhof, H., Burggraaf A. J. and Gellings, P. J., Oxygen semipermeability of erbia-stabilized bismuth oxide, Solid State Ionics, 53-56 (1), 468-460 (1992).

Bouwmeester, H. J. M., Methane activation on a $\mathrm{La}_{0.6} \mathrm{Sr}_{0.4} \mathrm{Co}_{0.8} \mathrm{Fe}_{0.2} \mathrm{O}_{3-\delta}$ perovskite catalytic and electrocatalytic results, Appl. Catal. A: Gen., 169 (2), 261-249 (1998).

Bouwmeester, H. J. M., Dense ceramic membranes for methane conversion, Catal. Today, 82 (1-4), 150-141 (2003).

Deng, Z. Q., Liu, W., Peng, D. K., Chen, C. S. and Yang, W. S., Combustion synthesis, annealing and oxygen permeation properties of $\mathrm{SrFeCo}_{0.5} \mathrm{O}_{\mathrm{y}}$ membranes, Mater. Res. Bull., 39 (7-8), 969-963 (2004).

Diethelm, S., Van Herle, J., Middleton, P. H. and Favrat, D., Oxygen permeation and stability of $\mathrm{La}_{0.4} \mathrm{Ca}_{0.6} \mathrm{Fe}_{1-\mathrm{x}} \mathrm{Co}_{\mathrm{x}} \mathrm{O}_{3-\delta}(\mathrm{x}=0,0.25,0.5)$ membranes, J. Power Sources, 118 (1-2), 275-270 (2003).

Diethelm, S. and Van Herle, J., Oxygen transport through dense $\mathrm{La}_{0.6} \mathrm{Sr}_{0.4} \mathrm{Fe}_{0.8} \mathrm{Co}_{0.2} \mathrm{O}_{3-\delta}$ perovskitetype permeation membranes, J. Eur. Ceram. Soc., 24 (6), 1323-1319 (2004).

Fagg, D. P., Shaula, A. L., Kharton, V. V. and Frade, J. R., High oxygen permeability in fluorite-type $\mathrm{Ce}_{0.8} \mathrm{Pr}_{0.2} \mathrm{O}_{2-\delta}$ via the use of sintering aids, J. Membr. Sci., 299 (1-2), 1-7 (2007).

Fan, C. G., Zuo, Y. B., Li, J. T., Lu, J. Q., Chen, C. 
S. and Bae, D. S., Highly permeable $\mathrm{La}_{0.2} \mathrm{Ba}_{0.8} \mathrm{Co}_{0.8} \mathrm{Fe}_{0.2-\mathrm{x}} \mathrm{Zr}_{\mathrm{x}} \mathrm{O}_{3-\delta}$ membranes for oxygen separation, Sep. Purif. Technol. 55 (1), 39-35 (2007).

Hendriksen, P. V., Larsen, P. H. and Mogensens, M., Prospects and problems of dense oxygen permeable membranes, Catal. Today, 56 (1-3), 295-283 (2000).

Ishihara, T., Yamada, T., Arikawa, H., Nishiguchi, H. and Takita, Y., Mixed electronic-oxide ionic conductivity and oxygen permeating property of $\mathrm{Fe}$, Co or Ni-doped $\mathrm{LaGaO}_{3}$ perovskite oxide, Solid State Ionics, 135 (1-4), 636-631 (2000).

Ishihara, T., Tsuruta, Y., Todaka, T., Nishiguchi, H. and Takita, Y., Fe doped $\mathrm{LaGaO}_{3}$ perovskite oxide as an oxygen separating membrane for $\mathrm{CH}_{4}$ partial oxidation, Solid State Ionics, 152-153: 714-709 (2002).

James, M., Cassidy, D., Wilson, K. F., Horvat, J. and Withers, R. L., Oxygen vacancy ordering and magnetism in the rare earth stabilised perovskite form of $\mathrm{SrCoO}_{3-\delta .}$. Solid State, Sci., 6 (7), 662-655 (2004).

Kharton, V. V., Viskup, A. P., Kovalevsky, A. V., Naumovich, E. N. and Marques, F. M. B., Ionic transport in oxygen-hyperstoichiometric phases with $\mathrm{KNiF}_{4}$-type structure, Solid State Ionics, 143 (3-4), 353-337 (2001).

Kharton, V. V., Kovalevsky, A. V., Tsipis, E. V., Viskup, A. P., Naumovich, E. N., Jurado, J. R. and Frade, J. R.. Mixed conductivity and stability of A-site-deficient $\mathrm{Sr}(\mathrm{Fe}, \mathrm{Ti}) \mathrm{O}_{3-\delta}$ perovskites, J. Solid State Electrochem., 7 (1) 36-30 (2002).

Kim, J. M., Hwang, G. J., Lee, S. H., Park, C. S., Kim, J. W. and Kim, Y. H., Properties of oxygen permeation and partial oxidation of membrane in $\mathrm{La}_{0.6} \mathrm{Sr}_{0.4} \mathrm{CoO}_{3-\delta} \quad$ (LSC)- $\mathrm{La}_{0.7} \mathrm{Sr}_{0.3} \mathrm{Ga}_{0.6} \mathrm{Fe}_{0.4} \mathrm{O}_{3-\delta}$ (LSGF) membranes, J. Membr. Sci., 250 (1-2), 16-11 (2005).

Kovalevsky, A. V., Kharton, V. V., Tikhonovich, V. N., Naumovich, E. N.,. Tonoyan, A. A, Reut, O. P., Boginsky, L. S., Oxygen permeation through $\mathrm{Sr}(\mathrm{Ln}) \mathrm{CoO}_{3-\delta} \quad(\mathrm{Ln}=\mathrm{La}, \mathrm{Nd}, \mathrm{Sm}, \mathrm{Gd})$ ceramic membranes, Mat. Sci. Eng. B, 52 (2): 105-116 (1998).

Kruidhof, H., Bouwmeester, H. J. M., Doom, R. H. E. V. and Burggraaf, A. J., Influence of orderdisorder transitions on oxygen permeability through selected nonstoichiometric perovskitetype oxides, Solid State Ionics, 63-65: 822-816 (1993).

Lu, H., Tong, J. H., Deng, Z. Q., Cong, Y. and Yang, W. S., Crystal structure, oxygen permeability and stability of $\mathrm{Ba}_{0.5} \mathrm{Sr}_{0.5} \mathrm{Co}_{0.8} \mathrm{Fe}_{0.1} \mathrm{M}_{0.1} \mathrm{O}_{3-\delta}(\mathrm{M}=\mathrm{Fe}, \mathrm{Cr}$, $\mathrm{Mn}, \mathrm{Zr}$ ) oxygen-permeable membranes, Mater.
Res. Bull., 41 (4), 495-483 (2006).

Maignan, A., Pelloquin, D., Flahaut, D. and Caignaert, V., Diluted magnetic interactions in an oxygen-deficient perovskite cobaltite: magneto resistance in the series $\mathrm{SrCo}_{1-\mathrm{x}} \mathrm{Sc}_{\mathrm{x}} \mathrm{O}_{3-\delta}(0<\mathrm{x} \leq 0.5)$, J. Solid State Chem., 177 (10), 3699-3693 (2004).

Qi, X. W. and Lin, Y. S., Electric conductivity and oxygen permeability of modified cerium oxides, J. Mater. Sci., 38 (5), 1079-1073 (2003).

Schiestel, T., Kilgus, M., Peter, S., Caspary, K. J., Wang, H. and Caro, J., Hollow fibre perovskite membranes for oxygen separation, J. Membr. Sci., 258 (1-2), 4-1 (2005).

Shao, Z. P., Dong, H., Xiong, G. X., Cong, Y. and Yang, W. S., Performance of a mixed-conducting ceramic membrane reactor with high oxygen permeability for membrane conversion, J. Membr. Sci., 183 (2): 192-181 (2001).

Shao, Z. P., Xiong, G. X., Dong, H., Yang, W. S. and Lin, L. W., Synthesis, oxygen permeation study and membrane performance of a $\mathrm{Ba}_{0.5} \mathrm{Sr}_{0.5} \mathrm{Co}_{0.8} \mathrm{Fe}_{0.2} \mathrm{O}_{3-\delta}$ oxygen-permeable dense ceramic reactor for partial oxidation of membrane to syngas, Sep. Purif. Techol., 25 (1-3), 116-97 (2001).

Shao, Z. P., Yang, W. S., Cong, Y., Dong, H., Tong, J. H. and Xiong, G. X., Investigation of the permeation behaviour and stability of a $\mathrm{Ba}_{0.5} \mathrm{Sr}_{0.5} \mathrm{Co}_{0.8} \mathrm{Fe}_{0.2} \mathrm{O}_{3-\delta}$ oxygen membrane, J. Membr. Sci., 172 (1-2), 188-177 (2000).

Shaula, A. L., Viskup, A. P., Kharton, V. V., Logvinovich, D. I., Naumovich, E. N., Frade, J. R. and Marques, F. M. B., Oxygen permeability of $\mathrm{LaGa}_{0.65} \mathrm{Ni}_{0.2} \mathrm{Mg}_{0.15} \mathrm{O}_{3-\delta}$ ceramics: effect of synthesis method, Mater. Res. Bull., 38 (2), 362353 (2003).

Tong, J. H., Yang, W. S., Zhu, B. C. and Cai, R., Investigation of ideal Zirconium-doped perovskite-type ceramic membrane materials for oxygen separation, J. Membr. Sci., 203 (1) 189175 (2002).

Tong, J. H., Yang, W. S., Cai, R., Zhu, B. C., Xiong, G. X. and Lin, L.W., Investigation on the structure stability and oxygen permeability of titanium-doped perovskite-type oxides of $\mathrm{BaTi}_{0.2} \mathrm{Co}_{\mathrm{x}} \mathrm{Fe}_{0.8-\mathrm{x}} \mathrm{O}_{3-\delta} \quad(\mathrm{x}=0.2-0.6)$, Sep. Purif. Technol., 32 (1-3), 299-289 (2003).

Tsai, C. Y., Dixon, A. G., Moser, W. R. and Ma, Y. H., Dense perovskite membrane reactors for partial oxidation of membrane to syngas, AIChE J., 43 (11), 2750-2741 (1997).

Tsiakaras, P., Athanasiou, C., Marnellos, G., Stoukides, M., Ten Elshof, J. E. and Trofimenko, N. E., Paulsen, J., Ullmann, H. and Muller, R., 
Structure, oxygen stoichiometry and electrical conductivity in the system Sr-Ce-Co-O. Solid State Ionics, 100 (3-4), 191-183 (1997).

Wiik, K., Aasland, S., Hansen, H. L., Tangen, L. L. and Ødegard, R., Oxygen permeation in the system $\mathrm{SrFeO}_{3-\mathrm{x}}-\mathrm{SrCoO}_{3-\mathrm{y}}$, Solid State Ionics, 152-153, 680-675 (2002).

Yaremchenko, A. A., Kharton, V. V., viskup, A. P., Naumovich, E. N., Tikhonovich, V. N and Lapchuk, N. M., Mixed electronic and ionic conductivity of $\mathrm{LaCo}(\mathrm{M}) \mathrm{O}_{3}(\mathrm{M}=\mathrm{Ga}, \mathrm{Cr}, \mathrm{Fe}$ or Ni). Solid State Ionics, 120 (1-4), 74-65 (1999).

Zhang, K., Ran, R., Ge, L., Shao, Z. P., Jin, W. Q. and $\mathrm{Xu}, \mathrm{N}$. P., Systematic investigation on new $\mathrm{SrCo}_{1-y} \mathrm{Nb}_{\mathrm{y}} \mathrm{O}_{3-\delta}$ ceramic membranes with high oxygen semi-permeability, J. Membr. Sci., 323, 436-443 (2008).
Zener, C., Interaction between the d-shells in the transition metals. II. Ferromagnetic compounds of manganese with perovskite structure, Phys Rev., 82, 403 (1951).

Zeng, P. Y., Ran, R., Chen, Z. H., Gu, H. X., Shao, Z. P. and Liu, S. M., Novel mixed conducting $\mathrm{SrSc}_{0.05} \mathrm{Co}_{0.95} \mathrm{O}_{3-\delta}$ ceramic membrane for oxygen separation, AIChE J., 53 (12), 3124-3116 (2007).

Zeng, P. Y., Ran, R., Chen, Z. H., Zhou, W., Gu, H. X., Shao, Z. P. and Liu, S. M., Efficient stabilization of cubic perovskite $\mathrm{SrCoO}_{3-\delta}$ by Bsite low concentration scandium doping combined with sol-gel synthesis, J. Alloy. Compd., 455, 470-465 (2008).

Zhu, X. F., Wang, H. H. and Yang, W. S., Novel cobalt-free oxygen permeable membrane, Chem. Comm., (9), 1131-1130 (2004). 